\title{
(C Biomedicine in Brazil
}

Brazil may best be known for Carnival celebrations, golden-sand beaches and soccer players who go by one name-but research into disease theraputics is now also starting to put the country on the scientific map. The number of biomedical publications with at least one Brazil-based author nearly tripled over the past decade, from around 4,500 papers in 2000 to close to 13,000 last year, according to data compiled for Nature Medicine by the University of São Paulo's André Frazão Helene. And even though the country churns out only a little over $2 \%$ of the world's biomedical output at present, that small number belies a larger trend toward innovative drug development and translational science. In the pages that follow, we highlight some of the strengths of Brazilian biomedicine and many of the challenges that lie ahead.

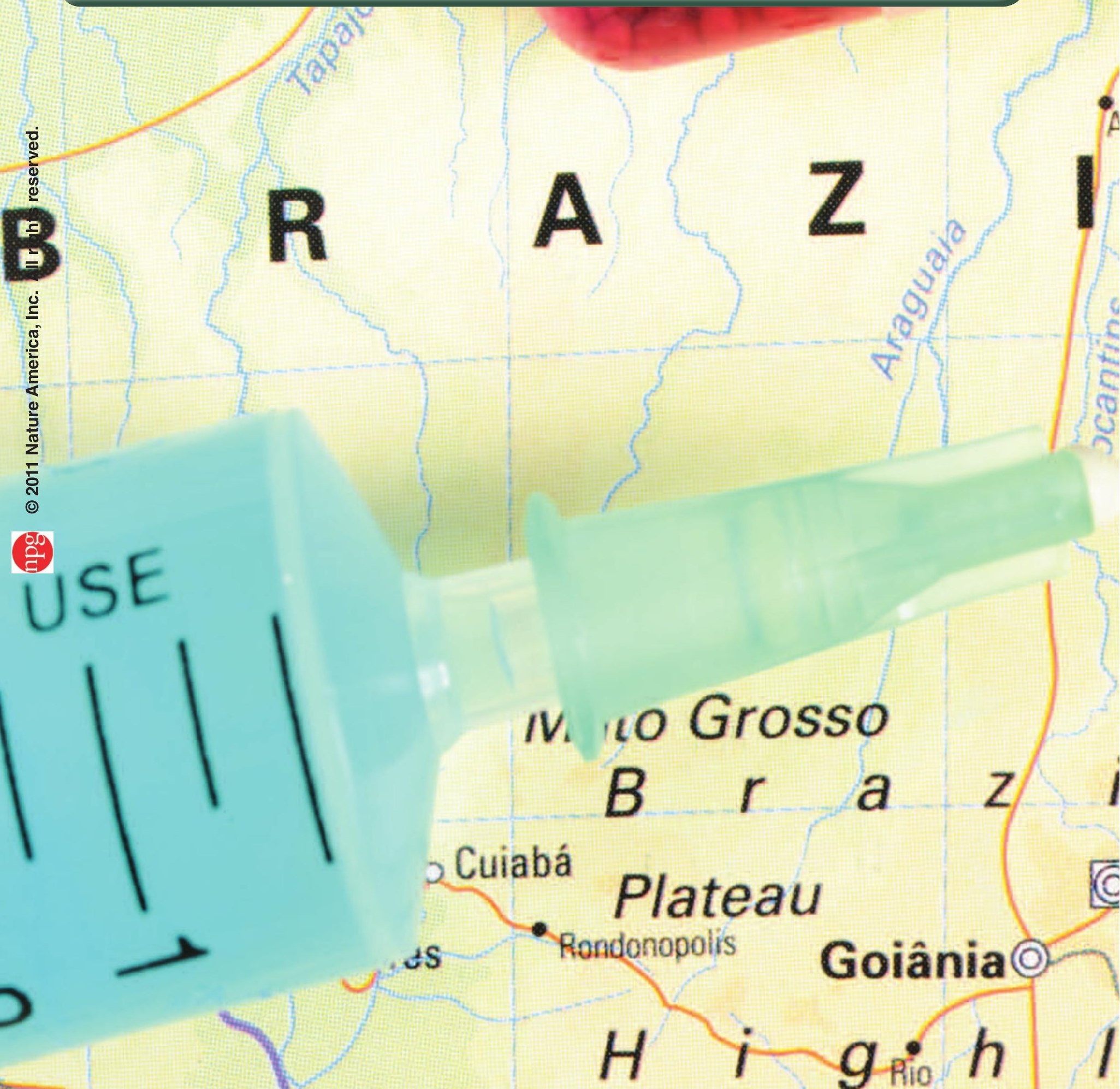

